\title{
Esterilização em Ortodontia: eficácia do esterilizador com esferas de vidro
}

Sônia Rodrigues Dutra*, Vagner Rodrigues Santos**, Leonardo Foresti Soares de Menezes***, Alexandre Fortes Drummond ${ }^{\star \star \star *}$, Ênio Lacerda Vilaça ${ }^{\star \star \star * \star}$, Paulo Henrique Amêndola Couto ${ }^{\star \star \star \star \star *}$

\begin{abstract}
Resumo
Objetivo: avaliar a efetividade do esterilizador com esferas de vidro Steri® ${ }^{\circledR} 350$, quanto ao controle de infecção das partes ativas dos alicates ortodônticos. Metodologia: foram utilizados nove alicates ortodônticos, previamente esterilizados em autoclave à temperatura de $121^{\circ} \mathrm{C}$, durante 20 minutos. Posteriormente, as partes ativas dos alicates foram contaminadas com Bacillus stearothermophilus. Logo após, as pontas dos alicates foram colocadas no Ster $i^{\circledR}$ 350, durante os períodos de $3,5,10,15,20,30$ e 40 segundos, em temperatura de $255^{\circ} \mathrm{C}$, para avaliar a eficácia da esterilização. Resultados e Conclusões: o esterilizador com esferas de vidro mostrou-se eficaz no controle do crescimento de Bacillus stearothermophilus nas partes ativas dos alicates ortodônticos, a partir de 10 segundos de exposição à temperatura de $255^{\circ} \mathrm{C}$.
\end{abstract}

Palavras-chave: Esterilização. Clínica em Ortodontia. Steri ${ }^{\circledR} 350$.

\section{INTRODUÇÃO E \\ REVISÃO DE LITERATURA}

Os profissionais da área ortodôntica, assim como aqueles de todas as especialidades odontológicas, devem instalar em seus consultórios barreiras para o controle de infecção cruzada. Estas barreiras incluem o uso de aparatologia pelo profissional e auxiliar (óculos, máscara, avental e luvas), desinfecção ou cobrimento de superfícies tocadas pelo paciente ou pelo profissional, "esterilização a frio" ou desinfecção de materiais termossensíveis e esterilização por calor de instrumentos não-termossensiveis ${ }^{6}$.

Esterilização é a eliminação de todas as formas de vida, inclusive de formas esporuladas de microrganismos, enquanto desinfecção é a eliminação dos microrganismos patogênicos de materiais inanimados, atingindo necessariamente as formas vegetativas de microrganismos, porém não as esporuladas ${ }^{16}$.

O objetivo do controle de infecção cruzada no consultório odontológico é prevenir a transmissão de doenças, considerando todo paciente, equipe odontológica e instrumental como um portador em potencial; deste modo, reduzindo o número de microrganismos potencialmente patogênicos, ao ponto que eles não sejam mais uma fonte de infecção ${ }^{1}$.

* Cirurgiã-dentista graduada pela FO-UFMG. Especialista em Ortodontia pela FO-UFMG.

** Mestre em Microbiologia pelo Institut National de Recherche Agronomique Jouy-en-Josas/França. Doutor em Anatomia Patológica Odontológica pela UFMG. Professor Associado do Departamento de Clínica, Patologia e Cirurgia da FO-UFMG.

*** Especialista e Mestre em Ortodontia pela UFRJ. Professor Assistente na Disciplina de Ortodontia da FO-UFMG.

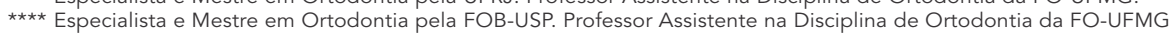

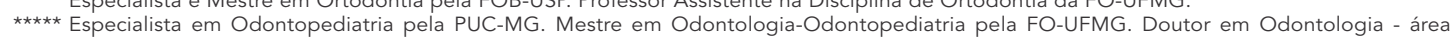
Clínica Integrada, pela FO-USP/SP. Professor adjunto do Departamento de Odontologia Restauradora da FO-UFMG.

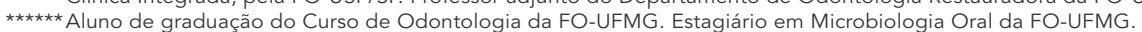


A boca é considerada o local de maior concentração de microrganismos dentro do consultório, tornando o ambiente clínico odontológico um meio propício para expor os profissionais e seus pacientes aos riscos biológicos. A transmissão dos microrganismos pode se dar por diversas vias, como: sangue, saliva, fluidos orgânicos, aerossóis e transferência de microrganismos presentes em objetos e superfícies ${ }^{15}$.

As doenças mais sérias que podem ser transmitidas entre os pacientes e a equipe odontológica são: hepatite $A$, hepatite $B$, hepatite não $A$ e não $B$, hepatite delta, tuberculose, herpes simples, Aids e CMV ou citomegalovírus, sendo que a prática ortodôntica é mais suscetível à infecção por hepatite $\mathrm{B}$, tuberculose, herpes e $\mathrm{CMV}^{11}$.

Em um consultório odontológico com um atendimento diário em torno de 20 pacientes, estima-se que, semanalmente, pelo menos um paciente com hepatite infecciosa tipo B (HBV) entre em contato com o profissional e seus auxiliares. A alta resistência do HBV, mostrando-se viável até seis meses à temperatura ambiente, torna esta característica muito importante nos consultórios de Ortodontia, onde uma grande quantidade de instrumentos é utilizada, ressaltando a necessidade de sua esterilização. $\mathrm{O}$ estabelecimento de barreiras contra a transmissão da hepatite B nos consultórios odontológicos torna esta conduta efetiva para os demais microrganismos, inclusive o vírus da AIDS, visto que o HBV é muito mais resistente e infeccioso ${ }^{4}$.

Estudos apontam que apenas um em cinco ortodontistas $(20,7 \%)$ esclarece seus pacientes na primeira consulta sobre as medidas de biossegurança adotadas em suas clínicas. Esta medida, quando adotada, não apenas ajuda a reforçar a imagem da clínica, como contribui para a conscientização das pessoas sobre a importância e os meios de proteção contra infecções cruzadas ${ }^{13}$.

Os ortodontistas têm demonstrado grande preocupação quando questionados sobre os cuidados relacionados à biossegurança. $\mathrm{O}$ item menos aceito por estes profissionais como meio de bios- segurança é o gorro $(15,88 \%)$. O uso da máscara atinge um índice de $90,20 \%$ de aceitação, as luvas $79,97 \%$, o jaleco $71,11 \%$ e os óculos de proteção aparecem com $75,95 \%$ de aceitação ${ }^{19}$.

Quando comparados aos clínicos gerais, os ortodontistas são menos complacentes com as devidas recomendações para controle de infecção ${ }^{12}$, sendo este um desafio para a Ortodontia, devido ao grande número de pacientes que são atendidos em curto espaço de tempo ${ }^{7}$.

A American Dental Association recomenda os seguintes métodos de esterilização: vapor sob pressão (autoclave), calor seco, vapor químico, gás óxido de etileno. Estes métodos destroem todos os microrganismos, incluindo esporos. Cada método de esterilização apresenta suas vantagens e desvantagens ${ }^{20}$.

Devido à alta rotatividade que apresenta o consultório ortodôntico, procura-se, cada vez mais, um método de esterilização rápida. Os esterilizadores com esferas de vidro têm mostrado efeitos bactericidas e viricidas, incluindo o vírus da hepatite $\mathrm{B}$, quando utilizados por 5 segundos a $233^{\circ} \mathrm{C}$. Testes laboratoriais têm mostrado que a autoclave química e a autoclave a vapor apresentam efeitos bactericidas contra Bacillus stearothermophilus e viricidas contra hepatite $\mathrm{B}$, influenza e vírus da pólio, quando utilizadas no tempo prescrito ${ }^{3}$. Para fins de esterilização, recomenda-se a utilização da autoclave a $121^{\circ} \mathrm{C}$ e $1 \mathrm{~atm} / \mathrm{cm}^{2}$, durante $20 \mathrm{minu}$ tos, e para a autoclave química $130^{\circ} \mathrm{C}$ e $1,4 \mathrm{~atm} /$ $\mathrm{cm}^{2}$ durante $20 \mathrm{~min}^{4}$.

O esterilizador com esferas de vidro tem se mostrado efetivo contra a maioria dos microrganismos e esporos. Há alguma evidência de que uma esterilização confiável de largo espectro ocorra apenas com pequenos instrumentos. Instrumentos volumosos não são recomendados, porque eles podem esfriar o meio, levando a uma temperatura abaixo daquela confiável para a esterilização. $\mathrm{O}$ padrão recomendado para esterilização é $232^{\circ} \mathrm{C}$ por 15 segundos ${ }^{10}$. Esterilização de pequenos instrumentos, como as limas endodônticas, pode ser feita no este- 
rilizador com esferas de vidro, devendo os demais instrumentos ser autoclavados antes do uso ${ }^{8}$.

Alguns estudos não consideram o esterilizador com esferas de vidro um método adequado para esterilização em Ortodontia, pois a grande desvantagem deste método seria a não-esterilização da área de apreensão dos instrumentos. Além disso, este método não esteriliza também as articulações dos alicates, onde freqüentemente entra algum tipo de fluido, como saliva ou sangue. Isto se deve à espessura do alicate, não havendo tempo suficiente para aquecer adequadamente o interior da articulação. Desde que não seja necessário aquecer todo o instrumento, a esterilização das superfícies ocorre somente com um tempo de 30 segundos a $250^{\circ} \mathrm{C}$, nos esterilizadores com esferas de vidro ${ }^{6}$.

A autoclave (calor úmido sob pressão) é considerada o método de eleição para esterilização em Ortodontia (eficaz tanto para instrumentos metálicos quanto para luvas, gaze, algodão e mesmo alguns plásticos), além da vantagem de apresentar um ciclo relativamente rápido ${ }^{2}$.

Considerando que o esterilizador com esferas de vidro Steri ${ }^{\circledR} 350$, cujo fabricante recomenda um tempo de 10 segundos a $250^{\circ} \mathrm{C}$ para esterilização dos instrumentos, vem sendo utilizado em larga escala nos consultórios de clínica ortodôntica, e sabendo-se que existem dúvidas quanto à sua eficácia com relação à esterilização dos instrumentais odontológicos utilizados em Ortodontia, este trabalho objetivou avaliar a efetividade do esterilizador com esferas de vidro quanto à esterilização das partes ativas dos alicates ortodônticos previamente contaminados com Bacillus stearothermophilus.

\section{MATERIAL E MÉTODOS}

Este estudo qualitativo, descritivo-analítico utilizou variáveis categóricas (nominais) para seu desenho ${ }^{5,9,14,17,18,21}$. Foi recrutado o universo de alicates ortodônticos $(\mathrm{n}=9)$ existentes no laboratório de pesquisa em Ortodontia da Faculdade de Odontologia da Universidade Federal de Minas Gerais. Todos os alicates apresentavam as mesmas caracte-

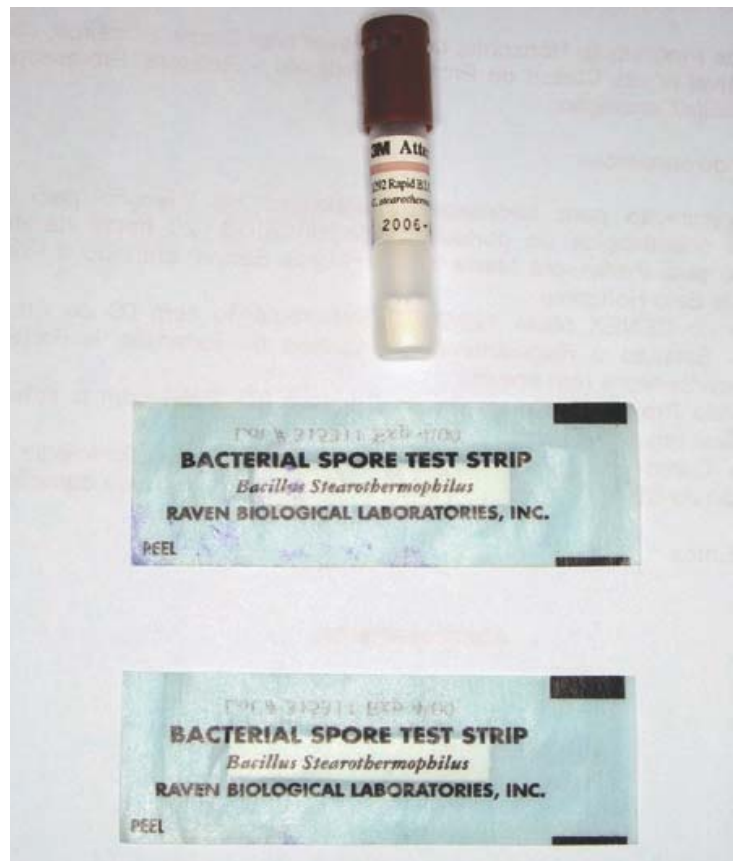

FIGURA 1 - Amostra de Bacillus stearothermophillus.

rísticas de constituição/liga metálica, de uso (sem ranhuras, desgastes ou fraturados) e foram todos adquiridos na mesma época, estando em excelente estado de uso.

Um estudo descritivo tem como objetivo a pura descrição de um fato médico. Sua principal característica é a ausência de um grupo de comparação. Quanto às variáveis categóricas, as mesmas podem ser do tipo nominal ou ordinal (caso exista uma ordem entre as classes). A variável nominal classifica uma característica do objeto a ser estudado: crescimento bacteriano em alicates ortodônticos - positivo ou negativo ${ }^{18}$.

Neste estudo foram utilizados o esterilizador com esferas de vidro, Steri ${ }^{\circledR}$ 350, da Klemmen, que apresenta em seu termostato temperatura mínima de $0^{\circ} \mathrm{C}$ e máxima de $350^{\circ} \mathrm{C}$; nove alicates ortodônticos previamente esterilizados em autoclave (calor úmido) à temperatura de $121^{\circ} \mathrm{C}$ (latm de pressão) durante $20 \mathrm{~min}$; e Bacillus stearothermophilus (ATCC 31198) (Fig. 1). Atualmente o Steri ${ }^{\circledR} 350$ está sendo comercializado com o nome de "Esterilizador de instrumentos 350" marca Au- 


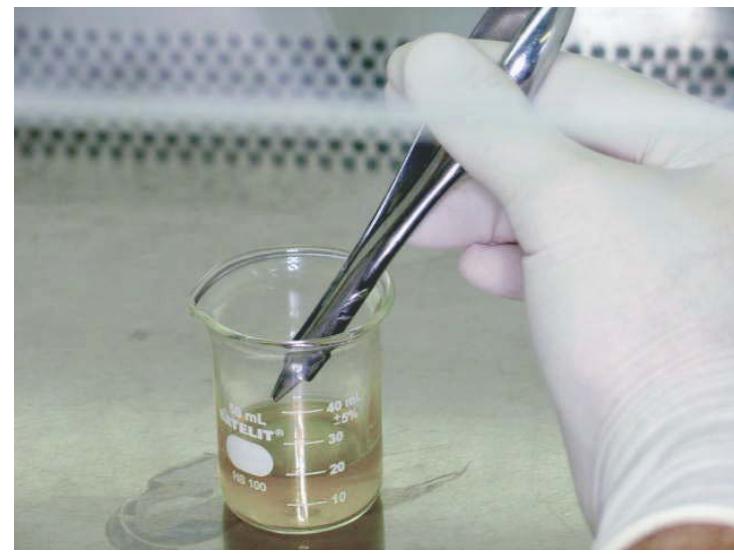

FIGURA 2 - Contaminação dos alicates com Bacillus stearothermophillus para testes de esterilização com Steri® 350 .

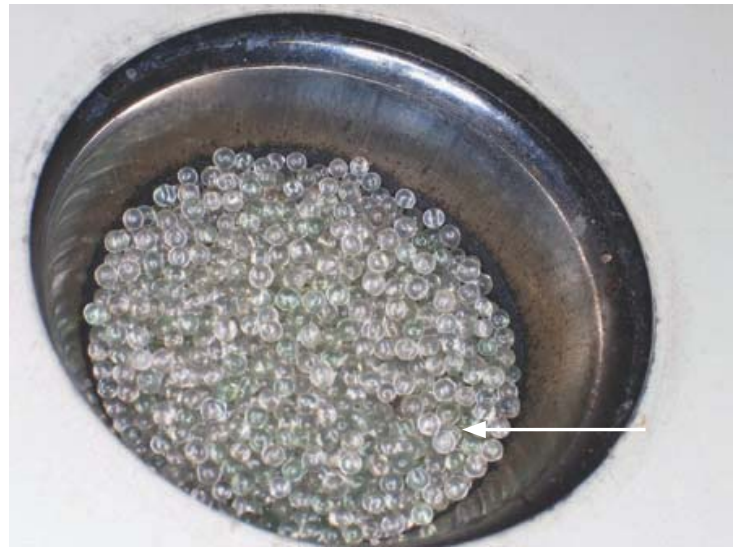

FIGURA 3 - Esterilizador com esferas de vidro (seta) Steri ${ }^{\circledR} 350$ utilizado nos testes.
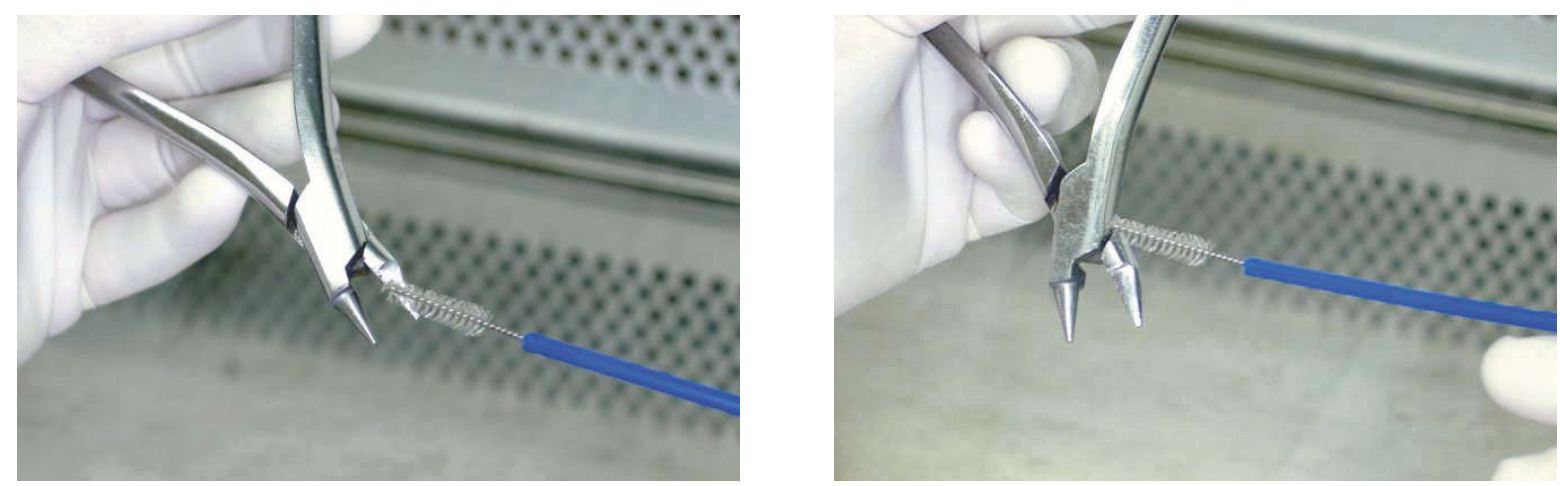

FIGURA 4 - Coleta de amostras dos alicates para teste de viabilidade de Bacillus stearothermophillus, após a esterilização.

reus, da Makeline Comercial Ltda.

Os Bacillus stearothermophilus são os microrganismos de escolha para testes padronizados de resistência microbiana aos métodos de esterilização por calor seco ou úmido, devido ao fato de suportarem elevadas temperaturas ${ }^{3}$. Os mesmos foram cultivados em Brain Heart Infusion (caldo BHI, Biobrás, Montes Claros/MG), durante 48 horas a $37^{\circ} \mathrm{C}$, em ambiente reduzido de $\mathrm{CO}_{2}$. Em seguida, as partes ativas dos alicates (pontas e articulações) (Fig. 2) foram contaminadas com os microrganismos e deixados no Steri ${ }^{\circledR}$ 350, nos períodos de 3, $5,10,15,20,30$ e 40 segundos, em temperatura de $255^{\circ} \mathrm{C}$ (Fig. 3). Os nove alicates ortodônticos utilizados neste estudo era do mesmo fabricante, marca, design e material. Cada alicate foi esterilizado em calor úmido, através de autoclave a $121^{\circ} \mathrm{C}$, durante 20 minutos, antes de ser contaminado com Bacillus stearothermophilus, para posteriormente ser esterilizado no Steri ${ }^{\circledR} 350$. A esterilização foi comprovada utilizando-se swabs embebidos em caldo BHI, através da fricção nas superfícies esterilizadas (Fig. 4) e, em seguida cultivados em caldo $\mathrm{BHI}$ a $37^{\circ} \mathrm{C}$, durante 48 horas, em ambiente reduzido de $\mathrm{CO}_{2}$. A não-turgidez do meio de cultura era indicativa do não-crescimento bacteriano e mostrava a eficácia do processo de esterilização (Fig. 5). Deve-se observar que, após cada período de esterilização no Ster ${ }^{\circledR} 350$ e friç̧ão da superfície do alicate para avaliação de crescimento bacteriano, o mesmo era 

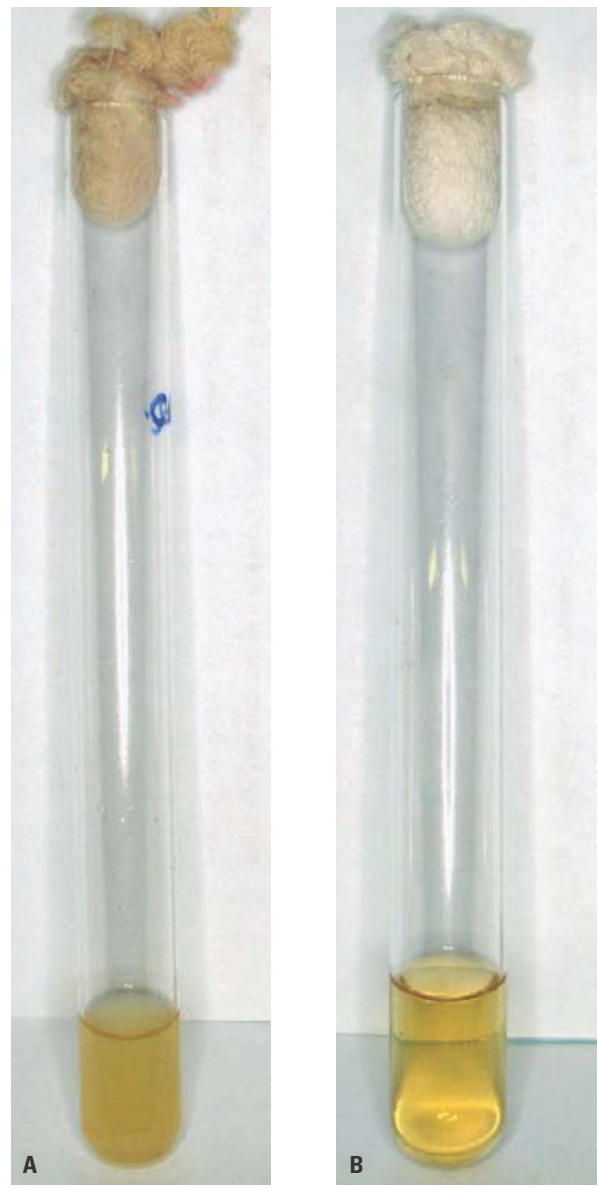

FIGURA 5 - Teste de viabilidade de Bacillus stearothermophilus em alicates esterilizados, após coleta em swabs nos tempos pré-determinados. A) Teste positivo de crescimento. B) Teste negativo.

novamente esterilizado em autoclave para, em seguida, ser contaminado com Bacillus stearothermophilus e levado ao esterilizador com esferas de vidro, em outro período de esterilização $(3,5,10$, $15,20,30$ e 40 segundos). Todos os alicates (1, 2, $3,4,5,6,7,8$ e 9) passaram pelo mesmo processo de esterilização e foram submetidos à avaliação de crescimento bacteriano.

Por se tratar de um estudo qualitativo, o cálculo amostral não se fez necessário, uma vez que o resultado esboçado se deu por observação de um corpo-de-prova, e o resultado é a expressão de uma qualidade positiva ou negativa, sem a intenção de comparação. A utilização do universo/amostra de alicates foi suficiente para esboçar um resultado, não ao acaso, que devido à disponibilidade de nove alicates da mesma marca, foram todos utilizados. $\mathrm{O}$ importante neste estudo é a observação/qualidade da esterilização - positivo ou negativo para crescimento bacteriano - e não o número de resultados para efeito comparativo. O desenho da pesquisa foi elaborado com o intuito de observar se há ou não crescimento bacteriano e, neste caso, o $\mathrm{n}=9$ é suficiente. Analisando, também, o $\mathrm{n}=9$, ou seja, nove alicates submetidos à análise de diferentes tempos de esterilização (3s, 5s, 10s, 15s, 20s, 30s, 40s), podese concluir que o mesmo corpo-de-prova (alicate), numa análise qualitativa, foi desdobrado em sete análises, ou seja, para um mesmo alicate o resultado será de sete possibilidades e, no total de $n=9$, de 63 possibilidades, o que exclui a possibilidade de acaso ou coincidência. Portanto, o estudo é viável e segue as normas da Epidemiologia $5,9,14,17,18,21$.

\section{RESULTADOS}

Os resultados encontram-se no quadro 1 .

Dos nove alicates ortodônticos submetidos à esterilização no Steri ${ }^{\circledR} 350$ nos tempos de 3, 5, 10, $15,20,30$ e 40 segundos, o número de alicates que permaneceram contaminados foi, respectivamente: $4,2,0,0,1,0$ e 0 .

Os resultados mostram que, a partir de 10 segundos à temperatura de $255^{\circ} \mathrm{C}$, o Steri ${ }^{\circledR} 350$ mostrou-se eficaz no controle de crescimento de Bacillus stearothermophilus.

Entre 3 e 5 segundos, mesmo ocorrendo inibição do crescimento, com relação ao número de alicates que permaneceram contaminados, ainda permaneceu significativo, considerando o número total de alicates igual a nove (Quadro 1).

\section{DISCUSSÃO}

No presente estudo, optou-se por testar a eficácia do esterilizador com esferas de vidro nos diversos tempos citados $(3,5,10,15,20,30$ e 40 segundos), para que fosse possivel extrapolar os tempos de esterilização encontrados na literatura consultada, que 
DUTRA, S. R.; SANTOS, V. R.; MENEZES, L. F. S.; DRUMMOND, A. F.; VILAÇA, E. L.; COUTO, P. H. A.

\begin{tabular}{|c|c|c|c|c|c|c|c|c|c|}
\hline $\begin{array}{c}\text { tempo de } \\
\text { esterilização }\end{array}$ & alicate 1 & alicate 2 & alicate 3 & alicate 4 & alicate 5 & alicate 6 & alicate 7 & alicate 8 & alicate 9 \\
\hline 3 segundos & - & $x$ & - & - & $\mathrm{x}$ & - & - & $\mathrm{x}$ & $\mathrm{x}$ \\
\hline 10 segundos & - & - & - & - & - & - & - & - & - \\
\hline 15 segundos & - & - & - & - & - & - & - & - & - \\
\hline 30 segundos & - & - & - & - & - & - & - & - & - \\
\hline 40 segundos & - & - & - & - & - & - & - & - & - \\
\hline
\end{tabular}

Quadro 1 - Valores médios iniciais, finais e desvios-padrão da distância entre a ponta da cúspide mesial até o ápice da raiz mesial do primeiro molar inferior permanente do grupo $2(X=$ Houve turvação do meio, indicando crescimento.- = Não houve turvação do meio).

foram: 5 segundos a $233^{\circ} \mathrm{C}, 15$ segundos a $232^{\circ} \mathrm{C}, 30$ segundos a $250^{\circ} \mathrm{C}$ e 10 segundos a $250^{\circ} \mathrm{C}$, segundo orientação do fabricante. A temperatura utilizada de $255^{\circ} \mathrm{C}$ foi a temperatura máxima alcançada pelo Steri ${ }^{\circledR} 350$, pois o mesmo não dispõe de regulador de temperatura.

Neste trabalho, o esterilizador com esferas de vidro mostrou-se eficaz no controle do crescimento de Bacillus stearothermophilus nas partes ativas dos alicates (pontas e articulações) a partir de 10 segundos de esterilização à temperatura de $255^{\circ} \mathrm{C}$, ficando muito próximo ao sugerido pelo fabricante (10 segundos a $250^{\circ} \mathrm{C}$ ).

$\mathrm{Na}$ literatura, foi encontrado que o esterilizador com esferas de vidro não esteriliza as articulações dos alicates, local onde, freqüentemente, entra algum tipo de fluido, como saliva ou sangue ${ }^{6}$. Este achado confronta-se com os resultados obtidos no presente estudo, pois o swab embebido em caldo BHI, além de ser friccionado na ponta do alicate ortodôntico, foi friccionado também na articulação do mesmo, para verificar crescimento bacteriano, conforme ilustrado na figura 4 . A partir de 10 segundos à temperatura de $255^{\circ} \mathrm{C}$, o esterilizador com esferas de vidro mostrou-se eficaz no controle de crescimento de Bacillus stearothermophilus nestas superfícies.

Além dos pequenos instrumentos que, conforme relatado na literatura ${ }^{8,10}$, podem ser submetidos com eficácia ao processo de esterilização no esterilizador com esferas de vidro, este método mostra-se, também, viável para instrumentos mais volumosos, como as partes ativas dos alicates ortodônticos utilizados neste estudo.

Métodos de esterilização rápida, como o utilizado no presente estudo, são de grande interesse em clínicas ortodônticas, onde um grande número de pacientes, geralmente atendidos em curto espaço de tempo interconsultas, implicaria em necessidade de aumento da quantidade de alicates, esbarrando no problema financeiro.

Para o controle da infecção cruzada é necessário que, durante o atendimento clínico no consultório ortodôntico, os profissionais envolvidos no atendimento façam uso de EPI (Equipamentos de proteção individual) completo, como também é de fundamental importância adotar todos os procedimentos básicos de esterilização e desinfecção nos consultórios. O cabo dos alicates ortodônticos, no entanto, continua sendo um problema, quanto à sua esterilização pelo $\operatorname{Steri}^{\circledR} 350$, pois o diâmetro do esterilizador permite a inserção apenas da parte ativa do alicate. Como o objetivo do presente estudo foi avaliar a efetividade do esterilizador com esferas de vidro quanto à esterilização das partes ativas dos alicates ortodônticos, não será discutido, no momento, a problemática da esterilização dos cabos. Cabe ressaltar a importância de se controlar o crescimento da microbiota nos cabos dos alicates, devendo os profissionais da área estar atentos quanto a isso. 


\section{CONCLUSÃO}

Considerando a metodologia empregada neste estudo, concluiu-se que o esterilizador com esferas de vidro Steri ${ }^{\circledR} 350$ mostrou-se eficaz no controle do crescimento de Bacillus stearothermophilus nas partes ativas (pontas e articulações) dos alica- tes ortodônticos, a partir de 10 segundos de exposição à temperatura de $255^{\circ} \mathrm{C}$.

\title{
Sterilization in Orthodontics: effectiveness of glass bead sterilizers
}

\begin{abstract}
Aim: The aim of this research was to evaluate the efficiency of Steri ${ }^{\circledR} 350$ glass bead sterilizer, on the infection control of the active part of the orthodontic pliers. Methods: Nine orthodontic pliers were sterilized in the steam autoclave at $121^{\circ} \mathrm{C}$ in 20 minutes and subsequently the active part of each plier was dipped in a culture for Bacillus stearothermophilus. Later, the active part of each plier was putted into the Steri ${ }^{\circledR} 350$ in the following periods: 3,5 , $10,15,20,30$, and 40 seconds at $255^{\circ} \mathrm{C}$ to evaluate the efficiency of this method in the infection control. Results and conclusions: This sterilization method has been effective to control the presence of Bacillus stearothermophilus on the active part of orthodontic pliers at $255^{\circ} \mathrm{C}$ in 10 seconds.
\end{abstract}

Key words: Sterilization. Clinics in Orthodontics. Steri ${ }^{\circledR} 350$.

\section{REFERÊNCIAS}

1. ASCENCIO, F.; LANGKAMP, H. H.; AGARWAL, S.; PETRONE, J. A.; PIESCO, N. P. Orthodontic marking pencils: a potencial source of cross-contamination. J. Clin. Orthod., Boulder, v. 32, no. 5, p. 307-310, 1998

2. BUfFARA, W.; PORTELLA, M. Q. Controle de infecção em Ortodontia. Ortodontia, São Paulo, v. 33, n. 2, p. 77-84, 2000.

3. CAMPBELL, P. M.; PHENIX, N. Sterilization in the orthodontic office. J. Clin. Orthod., Boulder, v. 20, no. 10, p. 684-686, 1986

4. CONSOLARO, A.; PINZAN, A.; URSI, W. J.; CUOGHI, O. A.; PINTO, P. R. S.; DIAZ, M. C. A. A hepatite B e a clínica ortodôntica. Ortodontia, São Paulo, v. 24, n. 2, p. 53-58, 1991.

5. DEAN, A. G. Epi-Info, version 6.04b: a word-processing database and statistics program for public health on IBMcompatible computers. Atlanta: Centers for Disease Control and Prevention, 1995.

6. DE SOUZA, R. S · GANDINI JÚNIOR, L G · PIZZOUTTO A. C. RAVELI, D. B.; SAKIMA, M. T. Teste de dois métodos rápidos de esterilização em Ortodontia. Ortodontia, São Paulo, v. 4, n. 1, p. 63-74, 1999.

7. DRAKE, D. L. Optimizing orthodontic sterilization techniques. J. Clin. Orthod., Boulder, v. 31, no. 8, p. 491-498, 1997.

8. HADDAD, A. J.; GIRARD JR., B.; BOUCLIN, R.; VALOIS, M.; LANDRY, G. R. Effectiveness of salt versus glass bead sterilizers. J. Can. Dent. Assoc., Toronto, v. 63, no. 6, p. 448-453, 1997.

9. JAKOBSEN, J. R. A survey of statistical methods used in dental literature. J. Dent. Educ., Washington, D.C., v. 63, no. 4, p. 350-352, 1999.

10. KIRCHHOFF, S.: SEKIJIMA, R. K.: MASUNAGA, M. I.: ALIZADEH, C. M. Sterilization in Orthodontic. J. Clin. Orthod., Boulder, v. 21, no. 5, p. 326-336, 1987

11. MOAWAD, K.; LONGSTAFF, C.; POLLACK, R. Barrier controls in the orthodontic office. J. Clin. Orthod., Boulder, v. 22, no. 2, p. 89-91, 1988.

12. McCARTHY, G. M.; MAMANDRAS, A. H.; MAcDONALD, J. K. Infection control in orthodontic Office in Canada. Am. J. Orthod. Dentofacial Orthop., St. Louis, v. 112, no. 3, p. 275-281, 1997.
13. NAKAMA, R.; GANDINI JÚNIOR, L. G.; CHIAVINI, P. C. R.; SAKIMA, M. T. Conquistar clientes na primeira consulta: uma abordagem prática para clínica particular de Ortodontia e Ortopedia. Rev. Clin. Ortodon. Dental Press, Maringá, v. 3, n. 1, p. 76-82, 2004

14. PEREIRA, M. G. Epidemiologia: teoria e prática. Rio de Janeiro: Guanabara Koogan, 1995.

15. RABELLO, S. R.; GODOY, C. V. C.; SANTOS, F. R. W. Presença de bactérias em instrumentais e superfícies do ambiente clínico odontológico. RBO, Rio de Janeiro, v. 58, n. 3, p. 184-187, 2001

16. ROSING, C. K. Controle de infecção: antissépticos e desinfetantes. In: WANNMACHER, L.; FERREIRA, M. B. C. Farmacologia clínica para dentistas. Rio de Janeiro: Guanabara Koogan, 1995. p. 138-140.

17. SIEGEL, S.; CASTELLAN, N. J. Non paramedic statistics for behavior and science. 2nd ed. New York: McJeaw-Book, 1988

18. SOARES, J. F.; SIQUEIRA, A. L. Introdução à estatística médica. Belo Horizonte: Coopmed, 2002.

19. SOUZA, C. E. V.; FERES, M. A. L.; PETRELLI, E. Quem somos e como estamos em relação à Ortodontia contemporânea no Brasil: terceiro estudo. J. Bras. Ortodon. Ortop. Facial, Curitiba, v. 8 , n. 47, p. 401-418, 2003.

20. VENDRELL, R. J.; HAYDEN, C. L.; TALOUMIS, L. J. Effect of steam versus dry-heat sterilization on the wear of orthodontic ligaturecutting pliers. Am. J. Orthod. Dentofacial Orthop., St. Louis, v. 121, no. 5, p. 467-471, 2002.

21. VIEIRA, S. Introdução à Bioestatística. 2. ed. Rio de Janeiro: Campus, 1991

\section{Endereço para correspondência \\ Sônia Rodrigues Dutra \\ Rua Silva Ortiz, 36 - Floresta \\ CEP: 30.150-130 - Belo Horizonte/MG \\ E-mail: soniardutra@ig.com.br}

